\title{
Design of Phase-Shifted Full-Bridge Switching Power Supply Transformer
}

\author{
Xiaoluo Jiang \\ College of Physics and Electric Information Engineering, Wenzhou University, Wenzhou, Zhejiang, China \\ Zhengqin Li \& Bingbing Liu \\ School of Information Engineering, City College of Wenzhou University, Wenzhou, Zhejiang, China
}

\begin{abstract}
The design of the switching power supply transformer, applied to the phase-shifted full-bridge inverter circuit as an example, is discussed in this paper. First, the main circuit of the phase-shifted full-bridge inverter is presented, and the basic design considerations from references are reviewed. Then the design processes are presented step by step, in which the detailed calculations are provided. Finally the testing data of some samples is given, and some suggestions are offered to get best efficiency and performance, which is helpful for practical design and production.
\end{abstract}

KEYWORD: Power Transformer; Switching Power Supply; Phase-Shifted Full-Bridge

\section{INTRODUCTION}

In recent years, high-frequency switching power supply is more widely used in applications. Due to limitations of the core material, the operating frequency of conventional high-frequency transformer is much low, usually around $20 \mathrm{kHz}$.With the development of power technology, miniaturization, high frequency and high power density have become the direction of the research and development trends in switching power supply areas. Transformer is a main component in switching power supply, and its importance on system performance is instantly increasing nowadays. How to design a proper transformer has become the main technology of switching power supply.

The design cases of the bipolar switching power supply transformers are less seen, or the volume of most transformers is great. For this reason, we studied the design of phase-shifted full-bridge switching power supply transformer, hoping to provide a useful reference for the optimized design of the bipolar switching power supply transformers.

\section{PHASE-SHIFTED FULL-BRIDGE CONVERTER CIRCUIT}

\subsection{Main circuit}

A phase-shifted full-bridge converter circuit of switching power supply is shown in Figure $1 . Q_{1}$ and $\mathrm{Q}_{3}$ are two of the same type MOSFET, called leading-legs, used to realize zero-voltage switching (ZVS). Each MOSFET has a capacitance in parallel, which is $\mathrm{C}_{1}$ and $\mathrm{C}_{2} . \mathrm{Q}_{2}$ and $\mathrm{Q}_{4}$ are two of the same type high-speed IGBT, called lagging-legs, used to realize zero current switching (ZCS). There is no capacitance needed in parallel with IGBT in lagginglegs. Each lagging-leg has a diode in serial, that's $\mathrm{D}_{1}$ and $\mathrm{D}_{2}$, for blocking reverse voltage and reverse current across the power switch in 0 state. $\mathrm{C}_{3}$ is the blocking capacitor and $\mathrm{L}$ is the resonant inductance, including the main transformer leakage inductance. D3 $\sim \mathrm{D}_{6}$ are rectifier diodes, forming full-wave rectifier circuit. $\mathrm{L}_{\mathrm{f}}$ is the output filter inductor and $\mathrm{C}_{4}$ is the output filter capacitor.

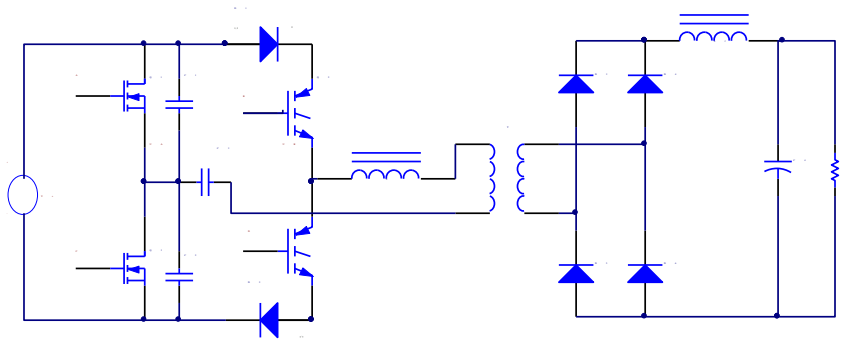

Figure 1 Main circuit structure diagram of the converter

\subsection{Features}

High-power MOSFET and high-speed IGBT are used in the circuit, which could reduce power consumption, increase the switching speed and reduce transformer size. Soft-switching technology, like Zero-voltage switching (ZVS) and zero current switching (ZCS) are used instead of the traditional hard-switching technology. The voltage of switches is zero when the switches turn on, while the current through the switches is zero when the switches cut 
off. Therefore switching voltage, current stress, surge and noise of power transistor are greatly reduced, leading to lower power consumption.

\section{DESIGN OF SWITCHING POWER SUPPLY TRANSFORMER}

High frequency transformer is the main part of the whole switching power supply. It directly related to the successful or not of the design of switching power supply.

\subsection{Design principles of switching power supply transformer}

\subsubsection{Temperature Rise}

The working temperature of the transformer is clearly stated in safety criteria. Absolute temperature of Class A transformer must be less than $90^{\circ} \mathrm{C}$, and that of Class B transformer should not exceed $110^{\circ} \mathrm{C}$. Therefore, the temperature rise must be designed within the specified range, and that is the criteria of transformer design.

\subsubsection{Cost}

Since the transformer is an important part of the switching power supply, its cost is also a major consideration. Trading off on the cost, size, quality of the transformer, getting optimized performance, is the main task of the switching power supply design.

\subsection{Design Specifications of Switching Power}

The following information is the design specification for a 2200 watts transformer, operating at $34 \mathrm{kHz}$, using Ap, Area Product approach. For a typical design example, assume with the following specification of supply transformer:

Input voltage, $\mathrm{V}$ in $=380 \mathrm{~V}$

Input frequency, $\mathrm{f}_{\mathrm{L}}=50 \mathrm{HZ}$

Output voltage, $\mathrm{Vo}=220 \mathrm{~V}$

Output current, Io $=10 \mathrm{~A}$

Operating frequency, fs $=34 \mathrm{kHz}$

Output power, $\mathrm{Po}=2200 \mathrm{~W}$

Estimated efficiency, $\eta=0.9$

Input power, $\mathrm{Pin}=\mathrm{Po} / \eta=2444 \mathrm{~W}$

Maximum temperature rise, $\Delta \mathrm{T}=50{ }^{\circ} \mathrm{C}$

In the actual design of transformer, iron consumption must be less than the allowable, to ensure the reliability of the transformer.

\subsection{Core selection of switching power supply transformer}

From performance requirements of the transformer, core material is basically considered only from Permalloy alloys, ferrite material, cobalt-based amorphous alloy and nanocrystalline alloys. The price of Permalloy alloys and cobalt-based amorphous alloy are high, which are several times around the price of ferrite material. The saturation flux density (Bs) of them is not very high, and the process is complex. Therefore, through comprehensive performance comparison of these materials, we chose ferrite material for its high saturation magnetic flux density Bs, good temperature stability and low prices. PC40 material from TDK Corporation is selected to make switching power transformers, which permeability up to $2300 \mathrm{H} / \mathrm{m}$, saturation magnetic induction Bs value at $25{ }^{\circ} \mathrm{C}$ for $510 \mathrm{mT}, 60{ }^{\circ} \mathrm{C}$ for $480 \mathrm{mT}, 100{ }^{\circ} \mathrm{C}$ for $390 \mathrm{mT}$, and high resistivity for $6.5 \Omega \cdot \mathrm{m}$.

\subsection{Parameter calculation of switching power supply transformer}

\subsubsection{Total apparent power of transformer}

Total apparent power of Transformer, $\mathrm{Pt}$, depends on the output power Po of the transformer and the form of the rectifier circuit as shown in Table 1 .

Table 1. Form of the rectifier circuit and total apparent power of transformer. [1]

\begin{tabular}{|l|l|}
\hline Type & Total apparent power \\
\hline Full-bridge Circuit Bridge Rectifier & $\mathrm{Pt}=\mathrm{Po}(1 / \eta+1)$ \\
\hline $\begin{array}{l}\text { Half-bridge Circuit Full-Wave } \\
\text { Rectifier }\end{array}$ & $\mathrm{Pt}=\mathrm{Po}(1 / \eta+\sqrt{2})$ \\
\hline $\begin{array}{l}\text { Push-pull Circuit Full-Wave } \\
\text { Rectifier }\end{array}$ & $\mathrm{Pt}=\sqrt{2} \mathrm{Po}(1 / \eta+1)$ \\
\hline
\end{tabular}

In which, $\eta$, is the transformer efficiency.

Our case uses a full bridge-circuit bridge rectifier,

so $P_{t}=P_{O}\left(\frac{1}{\eta}+1\right)=2200\left(\frac{1}{0.9}+1\right)=4644 \mathrm{~W}$

\subsubsection{Operating flux density}

Operating flux density is a very important parameter in the design of switching power supply transformer. It depends on the core material, structure, frequency, temperature, core unsaturated and other factors. If the value is too small, the size, weight and turns of the switching power supply transformer would increase, and the leakage inductance would also increase. According to practical experience, the maximum operating flux density, $\mathrm{Bm}$, is generally set within the range of $0.15 \sim 0.25 \mathrm{~T}$ in self-cooling mode, while in air-cooled mode, It is usually set within a larger number of $0.3 \mathrm{~T} \sim 0.4 \mathrm{~T}$.

\subsubsection{Establish Area Product (Ap)}

The value of Area Product, Ap, is selected applicable to or close to Ap calculated value of magnetic materials, structure and core specifications. 
Area Product of switching power supply may be stated as:

$$
A p=A e A w=\frac{P_{t}}{K_{f} K_{m} f_{s} B_{m} J}
$$

where $A_{e}$ is effective area of the center pole, $\mathrm{cm}^{2}$

$A_{w}$ is core winding window area, $\mathrm{cm}^{2}$

$\mathrm{K}_{\mathrm{f}}$ is waveform coefficient. The value of square wave is 4 and the value of sine wave is 4.44 .

$\mathrm{K}_{\mathrm{m}}$ is filing factor of window. It is related with wire thickness, winding process, the leakage inductance and stray capacitance, generally ranging from 0.2 to 0.4 .

$\mathrm{f}_{\mathrm{s}}$ is frequency of transformer switching.

$\mathrm{J}$ is current density, generally ranging from 2 $5 \mathrm{~A} / \mathrm{mm}^{2}$. Current density can be made bigger for air cooling

In this example, $\mathrm{K}_{\mathrm{f}}=4.0 ; \mathrm{K}_{\mathrm{m}}=0.4 ; \mathrm{f}_{\mathrm{s}}=34 \mathrm{KHz}$; and $\mathrm{J}$ $=5 \mathrm{~A} / \mathrm{mm}^{2}$.

The value of operating flux density, Bm, varies larger in the formula. In this example, EE cores of TDK material (PC40) are selected. Its operating frequency is $34 \mathrm{KHz}$ and temperature rise is $50^{\circ} \mathrm{C}$. It is working in air cooling mode. Theoretical calculations on core in references are much larger. Dual core is selected to reduce the size of transformer. As TDK Core data sheet shown in table 2 , we use the following two kinds of cores. One is EE42/42/21 dual core, whose area product is $10 \mathrm{~cm}^{4}$. Another is EE55/55/21 dual core, whose area product is $28.1 \mathrm{~cm}^{4}$. They both exceed the theoretical calculations of area product of core.

Table 2. Part date sheet of TDK Core

\begin{tabular}{|l|l|l|l|l|}
\hline \multirow{2}{*}{ Core } & Ae & Aw & Ap & $2 \times$ Ap \\
\cline { 2 - 5 } & $\mathrm{mm}^{2}$ & $\mathrm{~mm}^{2}$ & $\mathrm{~cm}^{4}$ & $\mathrm{~cm}^{4}$ \\
\hline EE55/55/21 & 354 & 397 & 14.05 & 28.1 \\
\hline EE42/42/21 & 182 & 275 & 5.0 & $10.0 "$ \\
\hline
\end{tabular}

\subsubsection{Calculate winding turns}

Primary winding turns of transformer is given by the following equation:

$$
N_{1}={\frac{V_{\text {in } \max }}{4 f B_{m} A_{e}}}^{[3]}
$$

where

$\mathrm{V}_{\text {inmax }}=$ maximum input voltage of transformer

Secondary voltage is given by the following equation:

$$
V_{s \max }=\frac{V_{o \text { max }}+V_{D}+V_{L f}}{D_{\max }}
$$

where $\mathrm{V}_{\text {smax }}=$ maximum secondary voltage; $\mathrm{V}_{\text {omax }}=$ maximum output voltage; $\mathrm{V}_{\mathrm{D}}=$ voltage of rectifier diode; $\mathrm{V}_{\mathrm{Lf}}=$ voltage of output filter inductor; $\mathrm{D}_{\max }=$ maximum duty ratio.
Primary-secondary turns ratio can be calculated as

follows: $K=\frac{V_{i n \min }}{V_{s \max }}$

where

$\mathrm{V}_{\text {inmin }}=$ minimum input voltage of transformer.

Secondary winding turns of transformer is given by the following equation:

$$
N_{2}=\frac{N_{1}}{K}
$$

According to the formula above, several sets of data calculations are done. Voltage parameters requirement and turns ratio calculation are shown in table 3. And transformer design and calculation parameters are shown in table 4.

Table 3. Form of input voltage and primary-secondary turns ratio calculated.

\begin{tabular}{|c|c|c|c|c|c|}
\hline \multirow{2}{*}{ Parameters } & Vinac & Vindc & Vo & Vsmax & $\mathrm{K}$ \\
\cline { 2 - 6 } & $\mathrm{V}$ & $\mathrm{V}$ & $\mathrm{V}$ & $\mathrm{V}$ & \\
\hline $\begin{array}{c}\text { The first } \\
\text { case }\end{array}$ & $380 \pm 10 \%$ & $440 \sim 585$ & $198 \sim 242$ & 288 & 1.53 \\
\hline $\begin{array}{c}\text { The second } \\
\text { case }\end{array}$ & $380 \pm 15 \%$ & $420 \sim 618 \mathrm{~V}$ & $180 \sim 280$ & 333 & 1.26 \\
\hline
\end{tabular}

where $\mathrm{Vinac}=\mathrm{AC}$ input voltage $; \mathrm{Vindc}=\mathrm{DC}$ input voltage $; \mathrm{Vo}=$ the output DC voltage range.

Table 4. Form of transformer design and calculation parameters.

\begin{tabular}{|c|c|c|c|}
\hline Parameters & $\mathrm{EE} 42 / 42 / 21$ & $\mathrm{EE} 42 / 42 / 21$ & $\mathrm{EE} 55 / 55 / 21$ \\
\hline $\mathrm{Bm}(\mathrm{T})$ & 0.3 & 0.25 & 0.2 \\
\hline $\mathrm{AP}\left(\mathrm{cm}^{4}\right)$ & 5.69 & 6.83 & 8.54 \\
\hline $\mathrm{N} 1$ & 40 & 48 & 32 \\
\hline $\mathrm{K}$ & 1.53 & 1.53 & 1.26 \\
\hline $\mathrm{N} 2(\mathrm{k}=1.53)$ & 27 & 32 & 20 \\
\hline $\mathrm{N} 2(\mathrm{k}=1.26)$ & 32 & 38 & 27 \\
\hline
\end{tabular}

\subsubsection{Winding wire selection}

Secondary winding area can be calculated as follows:

$$
A_{2}=\frac{I_{2}}{J}=\frac{10}{5}=2 \mathrm{~mm}^{2}
$$

Primary winding area can be calculated as follows:

$$
A_{1}=\frac{I_{1}}{J}=\frac{I_{2} / K}{J}=\frac{10 / 1.26}{5}=1.59 \mathrm{~mm}^{2}
$$

Taking into account the skin effect of high frequency current, the wire diameter should be selected to follow the principle of a diameter less than twice the penetration depth. When the wire diameter is less than twice of the maximum diameter decided by the penetration depth, it can be taken around the strands or flat copper winding. The penetration depth can be calculated as follows:

$$
\begin{aligned}
\Delta=\sqrt{\frac{2}{\omega \mu \gamma}} & =\sqrt{\frac{2}{2 \pi \times 34 \times 10^{3} \times 4 \pi \times 10^{-7} \times 58 \times 10^{6}}} \\
& =0.36 \mathrm{~mm}^{2}
\end{aligned}
$$


where $\omega=$ angular frequency; $\mu=$ wire permeability; and $\gamma=$ wire conductivity. For copper wire, $\mu=4 \pi \times$ $10^{-7} \mathrm{H} / \mathrm{m}$ and $\gamma=58 \times 10^{-6} \mathrm{~S} / \mathrm{m}$.

According to the results, the wire diameter should be selected less than $0.72 \mathrm{~mm}^{2}$.

\section{PRODUCTION AND TEST OF SWITCH POWER TRANSFORMER}

The production of high frequency transformer winding mainly refers to the windings of the transformer. Windings structure would affect the performance of transformer, reliability and the amount of wire. Two questions need to be considered. The first is how to minimize leakage inductance and the second is to reduce the eddy current consumption. These would help to improve the power conversion efficiency, reduce the surges of voltage, and improve the reliability of the inverter switches. In this example, sandwich structure is applied in the transformer windings.

According to the results of calculation and the actual project experience, the calculated parameters were adjusted and modified. No air gap was set between the cores. Several sets of transformers parameters were shown in Table 5.

Table 5. Form of transformer parameters.

\begin{tabular}{|l|l|l|l|}
\hline Parameters & The first set & The second set & The third set \\
\hline Dual core & EE42/42/21 & EE42/42/21 & EE55/55/21 \\
\hline Primary Turns & 40 & 45 & 40 \\
\hline Secondary Turns & 32 & 40 & 32 \\
\hline
\end{tabular}

Set I:

No air gap between the cores. The inductance of the primary winding was $14.26 \mathrm{mH}, \mathrm{Q}$ was 205 . The inductance of the secondary winding was $9.16 \mathrm{mH}, \mathrm{Q}$ was195.The leakage inductance was $4.8 \mu \mathrm{H}$

Testing after 5 minutes, the temperature of the transformer winding was $49^{\circ} \mathrm{C}$, and the cooling fin temperature of the power tube was $41{ }^{\circ} \mathrm{C}$

Ten minutes later, the temperature of the transformer winding rose to $109^{\circ} \mathrm{C}$, and the cooling fin temperature of the power tube was $52{ }^{\circ} \mathrm{C}$

Transformer coils and cores were very hot. The core was saturated apparently. From here you could learn, Bm value of 0.3 was too large.

Set II:

No air gap between the cores. The inductance of the primary winding was $12 \mathrm{mH}$, Q was 106 . The inductance of the secondary winding was $10 \mathrm{mH}, \mathrm{Q}$ was 104 .The leakage inductance was $1.45 \mu \mathrm{H}$.

Testing after 5 minutes, the chip temperature of the power tube was $82{ }^{\circ} \mathrm{C}$. The chip temperature of the rectifier diode was $77{ }^{\circ} \mathrm{C}$, and the temperature of the transformer winding was $78{ }^{\circ} \mathrm{C}$.
Thirty minutes later, the chip temperature of the power tube was $100{ }^{\circ} \mathrm{C}$. The chip temperature of the rectifier diode was $77{ }^{\circ} \mathrm{C}$, and the temperature of the transformer winding was $82{ }^{\circ} \mathrm{C}$.

Efficiency measured at light-load was above $88 \%$, and which at heavy-load was above $90 \%$.

Set III:

No air gap between the cores. The inductance of the primary winding was $6.53 \mathrm{mH}, \mathrm{Q}$ was 335 . The inductance of the secondary winding was $4.31 \mathrm{mH}, \mathrm{Q}$ was 352.The leakage inductance was $12.5 \mu \mathrm{H}$.

Testing after 10 minutes, the chip temperature of the power tube was $70^{\circ} \mathrm{C}$. The chip temperature of the rectifier diode was $72{ }^{\circ} \mathrm{C}$, and the temperature of the transformer winding was $80{ }^{\circ} \mathrm{C}$.

30 minutes later, the chip temperature of the power tube was $80{ }^{\circ} \mathrm{C}$. The chip temperature of the rectifier diode was $80^{\circ} \mathrm{C}$, and the temperature of the transformer winding was $88^{\circ} \mathrm{C}$.

Efficiency measured at light-load was above $90 \%$, and which at heavy-load was above $91 \%$.

\section{CONCLUSIONS}

From the above data, we can conclude that, in the design and production of switching power supply, dual core transformer can be used to reduce the size of the transformer. If smaller size is required, but efficiency is not most concerned, the second set transformer can be tried. If high efficiency is required, the third set transformer is appropriate. The size of the third set, of course, is slightly larger than those of the second set, but compared to those of single-core transformer, it has been reduced a lot. Of course, in the actual product design, it is necessary to slightly adjust the transformer parameters to achieve maximum efficiency and optimum performance.

\section{ACKNOWLEDGEMENTS}

This work was supported by General Project of Science Technology Department of Zhejiang Province (2010R50006-4).

\section{REFERENCES}

[1] Switching power supply transformer calculation method-People's Republic of China Ministry of Electronics Industry technical guidance documents SJ/Z2921-88.

[2] Colonel Wm.T.Mclyman.2004. Transformer and Inductor Design Handbook-Third Edition. Idyllwild, California, U.S.A.: Marcel Dekker, Inc.

[3] Shengli Liu.2001.Modern high-frequency switching power supply practical techniques. Beijing, China: Publishing House of Electronics Industry. 